\title{
Lower airway flow influences peak nasal inspiratory flow in school-aged children*
}

\author{
Helena Pité1,2, Lara Pimenta' ${ }^{1}$, Ana Cristina Henriques ${ }^{1}$, Inês Marques ${ }^{1}$, \\ Catarina Camarinha', Ana Verónica Lourenço', Isabel Almeida', Luís \\ Miguel Borrego ${ }^{1,2}$, Mário Morais-Almeida'
}

Rhinology 56: 3, 288-296, 2018

https://doi.org/10.4193/Rhin17.229

*Received for publication:

November 9, 2017

' Allergy Center, CUF Descobertas Hospital and CUF Infante Santo Hospital, Lisbon, Portugal 2 CEDOC, Chronic Diseases Research Center, NOVA Medical School / Faculdade de Ciências Médicas, Universidade Nova de Lisboa, Accepted: February 14, 2018 Lisbon, Portugal

Background: Rhinitis and asthma frequently coexist. Peak nasal inspiratory flow (PNIF) objectively evaluates nasal obstruction. Lower airway flow's impact on PNIF has seldom been analysed in children. We aimed to study the associations between PNIF and: (1)forced expiratory volume in one second $\left(\mathrm{FEV}_{1}\right)$ and peak expiratory flow (PEF) in children with allergic rhinitis and asthma and healthy controls; (2)allergic rhinitis and asthma control subjective evaluation.

Methods: Sequential assessments of PNIF before and after nasal decongestion and spirometry with bronchodilation test were performed in 65 children (6-12 years) with allergic rhinitis and asthma, and 24 gender, age-matched healthy controls. The Control of Allergic Rhinitis and Asthma Test in children (CARATkids) was used for control assessment. Associations were investigated by multiple linear regression models.

Results: Baseline and decongested PNIF correlated with baseline and post-bronchodilation FEV ${ }_{1}$ and PEF, observed independently of rhinitis and asthma diagnosis. The best model for PNIF included PEF, age and gender. No association was found between PNIF and CARATkids scores, except for nasal obstruction self-report.

Conclusion: In school-aged children, besides age and gender, PEF values should ideally be known to interpret PNIF values. PNIF can be complementary to subjective control assessment in children with allergic rhinitis and asthma.

Key words: asthma, children, Peak Expiratory Flow (PEF), Peak Nasal Inspiratory Flow (PNIF), rhinitis

\section{Introduction}

Rhinitis and asthma frequently coexist ${ }^{(1-4)}$. Allergic rhinitis is an independent risk factor for asthma persistence ${ }^{(1,5)}$; asthma prevalence is increased when rhinitis symptoms are persistent and severe ${ }^{(1,6,7)}$. Nasal obstruction is one of the main complaints in these patients ${ }^{(2-4,8)}$, due to mucosal inflammation.

The use of validated subjective scoring tools is highly recommended for the evaluation of rhinitis and asthma control(9-12). Furthermore, the assessment of a patient suffering of nasal obstruction should be based upon subjective and objective measurements, as both may not correlate well ${ }^{(9,11-13)}$. The Control of Allergic Rhinitis and Asthma Test (CARAT) is a simple and validated questionnaire that has the advantage of enabling the self-reported subjective concurrent assessment of rhinitis and asthma control in adults and in children (CARATkids) ${ }^{(14-16)}$. Howe- ver, no data exist on the association between CARAT questionnaires and objective measures of nasal patency.

Peak nasal inspiratory flow (PNIF) is a simple and validated measure of nasal airflow ${ }^{(11,12)}$, successfully used for the objective evaluation of rhinitis and its control ${ }^{(17-20)}$, including in children ${ }^{(21,}$ 22). Reference values for the paediatric population have been published, all measured in non-decongested noses ${ }^{(23-27)}$. Yet, it is important to measure PNIF values before and after decongestion to elicit the role of mucosal swelling ${ }^{(11,12)}$.

The impact of lower airway patency on PNIF should be conside$\operatorname{red}^{(11,12,28-30)}$. A bivariate correlation between baseline PNIF and peak expiratory flow (PEF) has been described in healthy children ${ }^{(26)}$, but no multivariable analysis including PEF was reported. Since a continuous increase in PNIF values has been consistently reported with children's age ${ }^{(23-27)}$, it is important to exclude that 
the observed association between PNIF and PEF is not a simple reflection of the normal growth (i.e., older children have larger airways and correspondingly higher nasal airflow).

Thus, we have investigated the association between PNIF before and after topical nasal alpha-adrenergic use and lower airway patency before and after inhaled beta 2 -agonist, in children with allergic rhinitis and asthma and healthy controls, when adjusted for possible confounders. We have also evaluated the association between PNIF and CARATkids questionnaire results, multiple sensitization to aeroallergens and exhaled nitric oxide levels (FeNO).

\section{Subjects and methods}

\section{Study design and participants}

Cross-sectional, exploratory study of 65 children (6-12 years) with allergic rhinitis and asthma recruited among patients attending the Allergy Center at CUF Descobertas Hospital in Lisbon, from May until October 2015. Rhinitis was defined as the presence of nasal itching/rhinorrhea/sneezing and/or nasal obstruction, occurring during $\geq 2$ consecutive days for $>1$ hour on most days $^{(1,8)}$. Allergic rhinitis was considered in children with rhinitis and self-reported symptoms upon aeroallergen exposure with positive skin prick test (SPT). Allergic rhinitis was classified according to the Allergic Rhinitis and its Impact on Asthma (ARIA) guidelines $^{(1,8)}$. Asthma was diagnosed by a history of respiratory symptoms in the previous year, such as wheeze, breathlessness, chest tightness and cough that varied over time and in intensity, together with documented positive bronchodilator reversibility testing ${ }^{(10)}$. A convenience-driven sampling was used, stratified by asthma control defined according to the Global Initiative for Asthma (GINA) guidelines ${ }^{(10)}$; children with controlled, partly controlled and uncontrolled asthma were recruited in an approximate 1:1:1 ratio.

Children with any other diagnosed respiratory or cardiac disease were excluded from this study. These encompassed diagnosed congenital or perinatal diseases including cardiopulmonary or neuromuscular diseases, pneumonia/pneumonitis, aspiration, cystic fibrosis, immunodeficiency, gastro-oesophageal reflux disease, adenoid hypertrophy, nasal septum deviation or nasal polyps. Children with asthma exacerbation, systemic corticosteroids use or acute disease (including respiratory infection) within four weeks of the study visit were also excluded.

Age and gender-matched controls without rhinitis and asthma were screened by no positive answers on the International Study of Asthma and Allergies in Childhood questionnaire ${ }^{(31)}$. Included children were non-atopic, without history of other diseases likely to interfere with the study (such as those described above) and no acute disease within the previous four weeks.

All diagnoses were validated by medical specialists, based on anamnesis, clinical files and medical examination including anterior rhinoscopy (performed in all children).
Informed consent was obtained from each child's parent/legal guardian. This study was approved by the Ethics Committee of CUF Descobertas Hospital and by the Portuguese Data Protection Authority.

\section{Measurements}

Prior to study visit, subjects had not taken any asthma or topical nasal medication for at least 12 hours and anti-histamines for seven days. Study visits occurred during the morning.

\section{CARATkids questionnaire}

All children with asthma and rhinitis and their parents answered the CARATkids before all other measurements ${ }^{(15)}$. Total score ( 0 - best control to 13 - worst control) was recorded, as well as, nasal obstruction report by the children and CARATkids total nasal score (varying from 0 to 3 , obtained by the sum of positive answers regarding nasal symptoms of "blocked nose", "sneezing" and "runny nose", in the past two weeks).

\section{Anthropometric measurements}

Accurate height $(\mathrm{cm})$ and weight $(\mathrm{Kg})$ were registered without shoes for all the included children.

\section{Respiratory function tests}

All nasal and lung function tests were performed by trained lung function technicians, all awarded with the European Respiratory Society Spirometry Driving Licence.

Bilateral PNIF was assessed using a nasal flow meter (In-Check Nasal, Clement Clarke International Ltd., Edinburgh, England). After mildly blowing their noses, the children were instructed to do a nasal inspiration with their mouths closed, from residual volume to total lung capacity, while using the facial mask without leakage of air or nose compression. The highest value out of three satisfactory maximal inspiration measurements was recorded. All measurements were taken with children sitting in an upright position.

Lower airway flow was assessed by forced expiratory volume in one second $\left(\mathrm{FEV}_{1}\right)$ and PEF, obtained by spirometry test (Jaeger MasterScreen ${ }^{\text {TM }}$ system from Carefusion with a Flow Spirometer (Lilly Pneumotacograph) with Software version - JLAB 5.31.0.83), performed and interpreted according to international recommendations ${ }^{(32)}$. Global Lung Initiative normative data was used. Bilateral topical nasal phenylephrine chlorhydrate at $2.5 \mathrm{mg} /$ $\mathrm{ml}$ was applied and a bronchodilation test was performed with $400 \mu \mathrm{g}$ of inhaled salbutamol administered using a chamber ${ }^{(32)}$. Then, decongested PNIF was obtained using the same procedures, as well as post-bronchodilator PEF and FEV .

Nasal reversibility was calculated by the Nasal Congestion Index $(\mathrm{NCl})^{(33)}$, as follows: $\mathrm{NCI}=$ [(decongested PNIF - baseline PNIF) / baseline PNIF]x100.

For the PNIF measurements recorded, the z-scores for age and 
Table 1. Study group characteristics.

\begin{tabular}{|c|c|c|c|c|c|c|}
\hline Characteristic & $\begin{array}{c}\text { All study } \\
\text { participants } \\
(\mathrm{n}=89)\end{array}$ & $\begin{array}{l}\text { Healthy controls } \\
\qquad(n=24)\end{array}$ & $\begin{array}{c}\text { Controlled } \\
\text { asthma }(n=20)\end{array}$ & $\begin{array}{l}\text { Partly controlled } \\
\text { asthma }(n=21)\end{array}$ & $\begin{array}{l}\text { Uncontrolled } \\
\text { asthma }(n=24)\end{array}$ & $\mathbf{p}$ \\
\hline Gender male, $\mathrm{n}(\%)$ & $50(56.2)$ & $12(50.0)$ & $10(50.0)$ & $15(71.4)$ & $13(54.2)$ & 0.439 \\
\hline Age months, median (min-max) & $115(73.0-155.0)$ & $116(73.0-155.0)$ & $105(74.0-155.0)$ & $115(76.0-148.0)$ & $128(78.0-155.0)$ & 0.106 \\
\hline Height cm, median (min-max) & $135(113.0-165.0)$ & $133(114.5-155.0)$ & $134(116.0-150.5)$ & $134(113.0-162.3)$ & $143(117.0-165.0)$ & 0.154 \\
\hline Weight Kg, median (min-max) & $34(17.0-67.0)$ & $31(17.0-48.0)$ & $31(20.0-53.0)$ & $35(17.0-54.0)$ & $39(22.0-67.0)$ & 0.103 \\
\hline $\begin{array}{l}\text { Allergic rhinitis classification (ARIA)* } \\
\text { Mild intermittent, } \mathrm{n}(\%) \\
\text { Moderate-severe intermittent, } \mathrm{n}(\%) \\
\text { Mild persistent, } \mathrm{n}(\%) \\
\text { Moderate-severe persistent, } \mathrm{n}(\%)\end{array}$ & $\begin{array}{c}5(5.6) \\
2(2.3) \\
11(12.4) \\
47(52.8)\end{array}$ & $\begin{array}{l}0(0.0) \\
0(0.0) \\
0(0.0) \\
0(0.0)\end{array}$ & $\begin{array}{c}4(20.0) \\
0(0.0) \\
5(25.0) \\
11(55.0)\end{array}$ & $\begin{array}{c}1(4.8) \\
2(9.5) \\
3(14.3) \\
15(71.4)\end{array}$ & $\begin{array}{c}0(0.0) \\
0(0.0) \\
3(12.5) \\
21(87.5)\end{array}$ & 0.028 \\
\hline Nasal topic corticosteroid use ${ }^{* \sharp}, \mathrm{n}(\%)$ & $23(33.8)$ & $0(0.0)$ & $6(30.0)$ & $8(38.1)$ & $9(37.5)$ & 0.832 \\
\hline Oral montelukast use ${ }^{* \#,} \mathrm{n}(\%)$ & $7(7.9)$ & $0(0.0)$ & $0(0.0)$ & $3(14.3)$ & $4(16.7)$ & 0.201 \\
\hline Inhaled corticosteroid use ${ }^{* \#}, \mathrm{n}(\%)$ & $37(41.6)$ & $0(0.0)$ & $12(60.0)$ & $14(66.7)$ & $11(45.8)$ & 0.351 \\
\hline Inhaled LABA use**, n (\%) & $20(22.5)$ & $0(0.0)$ & $6(30.0)$ & $4(19.0)$ & $10(41.7)$ & 0.259 \\
\hline Multiple sensitization*, n (\%) & $39(60.0)$ & $0(0.0)$ & $11(55.0)$ & $13(61.9)$ & $15(62.5)$ & 0.860 \\
\hline
\end{tabular}

ARIA - allergic rhinitis and its impact on asthma guidelines; min - minimum; max - maximum; LABA - long-acting beta ${ }_{2}$ agonist; ${ }^{*}$ - considering only children with rhinitis and asthma, ${ }^{*}$ - medication use reported by caregiver

gender were calculated according to the PNIF reference values proposed by Papachristou and collaborators(24).

\section{Fractional exhaled nitric oxide measurement}

The FeNO was measured with the $\mathrm{NIOX} \mathrm{Vero}{ }^{\circledR}$ system (Aerocrine, Sweden) using a single-breathing online method before respiratory function tests, according to current guidelines ${ }^{(34,35)}$.

\section{Skin prick tests}

The SPT were performed according to international recommendations ${ }^{(9,36)}$. The skin was pricked with steel lancets (Prick Lancetter ${ }^{\circledR}$, Hollister-Stier Laboratories, Spokane, WA, USA), and the following allergen extracts were applied: Dermatophagoides pteronyssinus, Dermatophagoides farinae, Lepidoglyphus destructor, Parietaria, grass pollen mixture, olive tree, Alternaria, dog and cat epithelium (Bial-Aristegui ${ }^{\circledR}$, Bilbao, Spain). Histamine hydrochloride $(10 \mathrm{mg} / \mathrm{ml})$ was used as a positive control; a saline solution was the negative control. A wheal mean diameter $\geq 3$ $\mathrm{mm}$ was considered a positive test.

Atopy was considered when at least one SPT was positive. Multiple sensitization was defined when SPT were positive to two or more of the following aeroallergen groups: house dust mites, pollens, moulds or pets.

\section{Statistical analysis}

Normal distribution of variables was assessed using the ShapiroWilk or Kolmogorov-Smirnov tests and histogram visual analysis.
Categorical variables were expressed as absolute and relative frequencies. Comparisons were performed with the Pearson's chi-square test. Continuous variables were expressed as the mean and standard deviation (SD), or median and extreme values in case of no normal distribution. Comparisons were performed with parametric independent t-test or one-way ANOVA or non-parametric Mann-Whitney or Kruskal-Wallis tests, followed by post-hoc multiple comparisons according to Bonferroni test. Correlations were analysed using Pearson's coefficient or Spearman's rank coefficient. Associations were further investigated by multivariable linear regression models for baseline and decongested PNIF; assumption of normally distributed residuals was fulfilled. Results were reported as beta-coefficients with $95 \%$ confidence intervals $(95 \% \mathrm{Cl})$.

$P$ values $<0.05$ were considered significant. Data analyses were performed with SPSS ${ }^{\circledR}$ version 24.0 for Windows (IBM SPSS,

Chicago, IL, USA).

\section{Results}

\section{Participants characteristics}

A total of 89 children were included. Participants' characteristics are summarized in Table 1. All children were Caucasian. No statistically significant differences were found regarding demographic and anthropometric parameters. Most patients had moderate-severe persistent allergic rhinitis (72.3\%). Allergic rhinitis classification by ARIA was associated with asthma control assessed according to GINA guidelines (Table 1). 
Table 2. Control of Allergic Rhinitis and Asthma Test for children (CARATkids) results.

\begin{tabular}{|c|c|c|c|c|c|c|c|c|c|}
\hline \multirow[b]{2}{*}{ Global score, median (min-max) } & \multicolumn{2}{|c|}{$\begin{array}{l}\text { Total of asthmatic } \\
\text { children } \\
(n=65)\end{array}$} & \multicolumn{2}{|c|}{$\begin{array}{l}\text { Controlled asthma } \\
\qquad(n=20)\end{array}$} & \multicolumn{2}{|c|}{$\begin{array}{l}\text { Partly controlled } \\
\text { asthma } \\
(n=21)\end{array}$} & \multicolumn{2}{|c|}{$\begin{array}{l}\text { Uncontrolled asthma } \\
\qquad(n=24)\end{array}$} & \multirow{2}{*}{$\begin{array}{c}\mathbf{p} \\
<0.001\end{array}$} \\
\hline & 4 & $(0-10)$ & 1 & $(0-8)$ & 4 & $(0-10)$ & 6 & $(2-10)$ & \\
\hline Nasal obstruction, n (\%) & 38 & $(58.5)$ & 9 & $(45.0)$ & 12 & $(57.1)$ & 17 & (70.8) & 0.221 \\
\hline Nasal score, n (\%) & & & & & & & & & 0.121 \\
\hline 0 & 10 & (15.4) & 4 & $(20.0)$ & 4 & (19.0) & 2 & $(8.3)$ & \\
\hline 1 & 12 & (18.5) & 7 & (35.0) & 4 & (19.0) & 1 & $(4.2)$ & \\
\hline 2 & 22 & (33.8) & 4 & $(20.0)$ & 7 & (33.3) & 11 & $(45.8)$ & \\
\hline 3 & 21 & (32.3) & 5 & $(25.0)$ & 6 & (28.6) & 10 & $(41.7)$ & \\
\hline
\end{tabular}

min - minimum; max - maximum

Table 3. Study group objective airway function and exhaled nitric oxide assessment.

\begin{tabular}{|c|c|c|c|c|c|c|c|c|c|c|c|}
\hline \multirow[b]{2}{*}{$\begin{array}{l}\text { Baseline PNIF L/min, } \\
\text { median (min-max) }\end{array}$} & \multicolumn{2}{|c|}{$\begin{array}{l}\text { All study } \\
\text { participants } \\
(\mathbf{n}=\mathbf{8 9})\end{array}$} & \multicolumn{2}{|c|}{$\begin{array}{l}\text { Healthy } \\
\text { controls } \\
(n=24)\end{array}$} & \multicolumn{2}{|c|}{$\begin{array}{l}\text { Controlled } \\
\text { asthma } \\
(n=20)\end{array}$} & \multicolumn{2}{|c|}{$\begin{array}{c}\text { Partly } \\
\text { controlled asthma } \\
(n=21)\end{array}$} & \multicolumn{2}{|c|}{$\begin{array}{l}\text { Uncontrolled } \\
\text { asthma } \\
(n=24)\end{array}$} & \multirow{2}{*}{$\begin{array}{c}\mathbf{p} \\
0.747\end{array}$} \\
\hline & 100.0 & $\begin{array}{l}(40.0- \\
170.0)\end{array}$ & 100.0 & $\begin{array}{l}(60.0- \\
150.0)\end{array}$ & 100.0 & $\begin{array}{l}(40.0- \\
150.0)\end{array}$ & 100.0 & $\begin{array}{l}(50.0- \\
150.0)\end{array}$ & 100.0 & $\begin{array}{l}(40.0- \\
170.0)\end{array}$ & \\
\hline $\begin{array}{l}\text { Decongested PNIF L/ } \\
\text { min, median (min-max) }\end{array}$ & 110.0 & $\begin{array}{l}(50.0- \\
210.0)\end{array}$ & 110.0 & $\begin{array}{l}(80.0- \\
190.0)\end{array}$ & 110 & $\begin{array}{l}(50.0- \\
200.0)\end{array}$ & 120.0 & $\begin{array}{l}(60.0- \\
190.0)\end{array}$ & 120.0 & $\begin{array}{l}(80.0- \\
210.0)\end{array}$ & 0.339 \\
\hline $\begin{array}{l}\text { Baseline PNIF z-score, } \\
\text { mean (SD) }\end{array}$ & -0.77 & $(0.94)$ & -0.70 & $(0.94)$ & -0.80 & (1.06) & -0.65 & $(0.66)$ & -0.93 & $(1.06)$ & 0.630 \\
\hline $\begin{array}{l}\text { Decongested PNIF z- } \\
\text { score, mean (SD) }\end{array}$ & -0.07 & $(0.93)$ & -0.05 & (1.05) & -0.16 & $(1.00)$ & 0.12 & $(0.82)$ & -0.17 & $(0.87)$ & 0.617 \\
\hline $\begin{array}{l}\text { Nasal congestion index } \\
\% \text {, median (min-max) }\end{array}$ & 21.43 & $\begin{array}{l}(-10.00- \\
175.00)\end{array}$ & 23.61 & $\begin{array}{l}(0.00- \\
66.67)\end{array}$ & 19.26 & $\begin{array}{l}(-10.00- \\
100.00)\end{array}$ & 20.00 & $\begin{array}{c}(-10.00- \\
83.33)\end{array}$ & 22.48 & $\begin{array}{l}(-4.55- \\
175.00)\end{array}$ & 0.984 \\
\hline $\begin{array}{l}\text { Baseline PEF L/s, mean } \\
\text { (SD) }\end{array}$ & 3.95 & $(0.97)$ & 3.96 & $(0.87)$ & 3.98 & (0.96) & 3.98 & $(1.26)$ & 3.90 & $(0.83)$ & 0.993 \\
\hline $\begin{array}{l}\text { Baseline PEF z-score, } \\
\text { mean (SD) }\end{array}$ & -0.41 & (0.94) & -0.25 & $(0.79)$ & -0.07 & (1.08) & -0.49 & (0.85) & -0.77 & $(0.96)$ & 0.070 \\
\hline $\begin{array}{l}\text { Post-beta }{ }_{2} \text { agonist PEF } \\
\text { L/s, mean (SD) }\end{array}$ & 4.30 & (0.99) & 4.28 & $(0.83)$ & 4.27 & $(1.02)$ & 4.17 & $(1.25)$ & 4.47 & $(0.87)$ & 0.776 \\
\hline $\begin{array}{l}\text { Post-beta }{ }_{2} \text { agonist PEF } \\
\text { z-score, mean (SD) }\end{array}$ & 0.01 & (0.81) & 0.21 & $(0.77)$ & 0.22 & $(0.92)$ & -0.20 & (0.91) & -0.18 & $(0.59)$ & 0.135 \\
\hline $\begin{array}{l}\text { Baseline } F E V_{1} L \text {, mean } \\
\text { (SD) }\end{array}$ & 1.88 & $(0.47)$ & 1.91 & $(0.48)$ & 1.93 & $(0.47)$ & 1.86 & $(0.57)$ & 1.83 & (1.89) & 0.894 \\
\hline $\begin{array}{l}\text { Baseline FEV } \text { z-score, } \\
\text { mean (SD) }\end{array}$ & 0.32 & (1.58) & 0.85 & (1.07) & 1.26 & (1.65) & 0.19 & (1.30) & -0.88 & $(1.42)$ & $<0.001$ \\
\hline $\begin{array}{l}\text { Post-beta }{ }_{2} \text { agonist FEV } \\
\text { L, mean (SD) }\end{array}$ & 2.05 & $(0.51)$ & 1.98 & $(0.47)$ & 2.04 & $(0.53)$ & 2.01 & (0.59) & 2.15 & $(0.48)$ & 0.698 \\
\hline $\begin{array}{l}\text { Post-beta }{ }_{2} \text { agonist FEV } \\
\text { z-score, mean (SD) }\end{array}$ & 1.22 & $(1.35)$ & 1.30 & (1.09) & 1.79 & (1.47) & 1.11 & (1.35) & 0.75 & $(1.36)$ & 0.079 \\
\hline $\begin{array}{l}\text { Positive bronchodila- } \\
\text { tion test, } \mathrm{n}(\%)\end{array}$ & 25 & $(28.1)$ & 1 & $(4.2)$ & 0 & $(0.0)$ & 6 & (28.6) & 18 & (75.0) & $<0.001$ \\
\hline $\begin{array}{l}\text { FeNO ppb, median } \\
\text { (min-max) }\end{array}$ & 12 & $(0-104)$ & 5 & $(0-24)$ & 10 & $(0-87)$ & 15 & $(0-94)$ & 29 & $(7-104)$ & $<0.001$ \\
\hline
\end{tabular}

PNIF - peak nasal inspiratory flow; PEF - peak expiratory flow; FEV 1 - forced expiratory volume in one second; FeNO - exhaled nitric oxide; min - minimum; max - maximum; SD - standard deviation 
Table 4. Correlation coefficients between Peak Nasal Inspiratory Flow and demographic/anthropometric and lung function variables.

\begin{tabular}{|c|c|c|c|c|}
\hline \multirow[t]{2}{*}{ Variables } & \multicolumn{2}{|c|}{ Baseline PNIF (L/min) } & \multicolumn{2}{|c|}{ Decongested PNIF (L/min) } \\
\hline & rho & $\mathbf{p}$ & rho & $\mathbf{p}$ \\
\hline Age (months) & 0.281 & $(0.008)$ & 0.445 & $(<0.001)$ \\
\hline Height (cm) & 0.288 & $(0.006)$ & 0.452 & $(<0.001)$ \\
\hline Weight (Kg) & 0.358 & $(0.001)$ & 0.488 & $(<0.001)$ \\
\hline Baseline $\mathrm{FEV}_{1}(\mathrm{~L})$ & 0.322 & $(0.002)$ & 0.453 & $(<0.001)$ \\
\hline Baseline FEV 1 (z-score) & - & ns & - & ns \\
\hline Post-beta ${ }_{2}$ agonist $\mathrm{FEV}_{1}$ (L) & 0.299 & $(0.004)$ & 0.475 & $(<0.001)$ \\
\hline Post-beta ${ }_{2}$ agonist $\mathrm{FEV}_{1}$ (z-score) & - & ns & - & ns \\
\hline Baseline PEF (L/s) & 0.404 & $(<0.001)$ & 0.482 & $(<0.001)$ \\
\hline Baseline PEF (z-score) & 0.321 & $(0.002)$ & - & ns \\
\hline Post-beta ${ }_{2}$ agonist PEF (L/s) & 0.341 & $(0.001)$ & 0.476 & $(<0.001)$ \\
\hline Post-beta ${ }_{2}$ agonist PEF ( $z$-score) & 0.226 & $(0.033)$ & - & ns \\
\hline
\end{tabular}

rho - Spearman rank correlation coefficient; PNIF - peak nasal inspiratory flow; FEV - forced expiratory volume in one second; PEF - peak expiratory flow; ns - not significant

\section{CARATkids scores}

The median CARATkids score in children with rhinitis and asthma was 4 , varying from 0 to 10 . This score was associated with asthma control but no statistically significant differences were found regarding CARATkids nasal score or nasal obstruction self-report (Table 2).

The CARATkids score was associated with ARIA rhinitis classification, the worst values in moderate-severe persistent rhinitis (Bonferroni post-hoc testing, $\mathrm{p}=0.002$ ).

\section{Objective measurements}

Table 3 summarizes the upper and lower airway function and FeNO assessment results. No statistically significant differences were found in PNIF values or $\mathrm{NCl}$ comparing healthy children versus children with rhinitis and asthma, either reporting nasal obstruction or not. Children with rhinitis and asthma reporting nasal obstruction in the past two weeks in the CARATkids questionnaire had mean baseline PNIF z-scores of -1.02 (SD 1.01) versus -0.68 (SD 0.95) in healthy children $(p=0.185)$.

Obstructive lower airway flow limitation was found in $27 \%$ of the children, with $\mathrm{FEV}_{1} \mathrm{z}$-score varying from -3.49 to 1.17. Lower $\mathrm{FEV}_{1}$ z-score and higher FeNO levels were found in children with asthma, the worst values in uncontrolled asthmatics (Bonferroni post-hoc testing, $\mathrm{p} \leq 0.006)$. No associations were found between PNIF and asthma control (assessed according to GINA guidelines) or ARIA classification of allergic rhinitis.

\section{Association between PNIF and CARATkids scores}

In children with rhinitis and asthma, those reporting nasal obstruction in the CARATkids questionnaire had lower baseline PNIF z-scores (mean -1.02 (SD 1.01) versus mean -0.49 (SD 0.73), $\mathrm{p}=0.018$ ). This association was independent of PEF and FEV 1 . No other associations were found between PNIF and CARATkids scores.

\section{Association between PNIF and demographic/anthropome- tric variables \\ Baseline and decongested PNIF values correlated with age, height and weight (Table 4). Both values were higher in boys, although this difference was not statistically significant (median decongested PNIF 120.0L/min (70.0L/min-210.0L/min) in boys versus $110.0 \mathrm{~L} / \mathrm{min}(50.0 \mathrm{~L} / \mathrm{min}-190.0 \mathrm{~L} / \mathrm{min})$ in girls, $\mathrm{p}=0.117)$.}

\section{Association between PNIF, lung function variables and FeNO} Baseline and decongested PNIF correlated with baseline and post-beta ${ }_{2}$ agonist FEV $_{1}$ and PEF (Table 4). After adjusting the models for gender and age, the estimated change in decongested PNIF per $1 \mathrm{~L}$ increase in post-beta ${ }_{2} \mathrm{FEV}_{1}$ or $1 \mathrm{~L} / \mathrm{s}$ increase in PEF (beta-coefficients) were $29.73 \mathrm{~L} / \mathrm{min}(95 \% \mathrm{Cl} 17.80-41.67$, adjusted $\left.r^{2}=0.248, p<0.001\right)$ and $17.12 \mathrm{~L} / \mathrm{min}(95 \% \mathrm{Cl} 11.06-23.19$, adjusted $\left.r^{2}=0.293, p<0.001\right)$, respectively. Baseline values of PNIF were also significantly associated with $\mathrm{FEV}_{1}$ (beta-coefficient 15.78L/min; 95\%Cl 3.92-27.64, adjusted $\mathrm{r}^{2}=0.105, \mathrm{p}=0.008$ ) and PEF (beta-coefficient 10.40L/min; 95\%Cl 4.77-16.02, adjusted 
$\left.r^{2}=0.164, p<0.001\right)$

The backward elimination procedure eliminated the variables height and weight. The associations between PNIF and FEV or $_{1}$ PEF were observed independently of rhinitis and asthma diagnosis, CARATkids scores, multiple sensitization and montelukast, nasal or inhaled corticosteroid or long-acting beta ${ }_{2}$-agonist use. The best equation for decongested PNIF (L/min) was (adjusted $\left.r^{2}=0.309, p<0.001\right): 30.32+11.38 \times$ baseline PEF $(L / s)+0.34 \times$ age (months) $+14.89 \times$ gender [0-female; 1-male].

A correlation was found between baseline PNIF (L/min) and PEF z-score (Table 4). Baseline PNIF z-score was also associated with FEV $z$-score $(r=0.228, p=0.031)$ and PEF $z$-score $(r=0.307$, $p=0.003)$; this was observed independently of nasal obstruction report.There was no association between reversibility of the upper and lower airways. No association was found between PNIF and FeNO levels.

\section{Discussion}

A consistent and independent correlation between PNIF and lower airway patency was found in school-aged children. Thus, this study strengthens that, ideally, it is important to consider at least PEF values, besides age and gender, when assessing nasal airflow by means of PNIF in children. PNIF can provide complementary objective information to subjective control assessment in children with allergic rhinitis and asthma.

We have evaluated the association between PNIF and lower airway patency measures in school-aged children, when adjusted to potential confounders. Sequential upper and lower airway standardized evaluations of the same individual were performed, reporting PNIF values before and after nasal topical alpha-adrenergic use and PEF and FEV 1 values before and after inhaled beta ${ }_{2}$-agonist. A balanced sample of patients comprising different asthma control levels was studied, together with age and gender-matched healthy controls. Consistent correlations between upper and lower airway flow were found. These correlations persisted after adjusting to age, gender, height and weight, suggesting that the association between upper and lower airflow measures is independent and not a simple reflection of growth or body size. The correlations found between PNIF and PEF expressed in z-scores (which is age, gender and heightindependent) also support our conclusions. Furthermore, this study strengthens that objective measurements of nasal flow and subjective symptoms scores may not be correlated, as we found no associations between PNIF and the CARATkids questionnaire scores, except for nasal obstruction self-report in the past two weeks and PNIF expressed in z-scores in children with allergic rhinitis and asthma.

This study's main limitations are its cross-sectional, exploratory design and the lack of children with asthma or rhinitis alone. Most children with asthma also have rhinitis $(1,5,9,10)$, and we did include asthmatic children with different levels of disease control and lung function tests results, but still inclusion of children with asthma or rhinitis only is relevant. Another limitation is the lack of children of other ethnicity, which limits our results only to Caucasians. Further studies with larger heterogeneous samples are needed to confirm our results. Despite the fact that all diagnoses were validated by medical specialists (based on anamnesis, clinical files and medical examination including anterior rhinoscopy), no nasal endoscopy or imaging techniques were performed in this study. Therefore, we could not firmly rule out adenoid hypertrophy or nasal septum deviation, but only excluded children with known or suspected diagnosis or with observable anatomical nasal abnormality on anterior rhinoscopy. Although baseline PNIF correlated with PEF and FEV 1 before and after bronchodilator use, we did not retest for PNIF after the single use of bronchodilator and therefore the clinical usefulness of PNIF after bronchodilator only was not tested.

The fact that nasal flow can be influenced by lower airway status has long been a concern ${ }^{(12)}$. Studies in adults have suggested an independent correlation between PNIF and PEF ${ }^{(28)}$, or FEV ${ }_{1}{ }^{(29)}$. Although initially considered a limitation of PNIF, the concept of a single disease of the airways has changed this view, and the impact of the lower airways is now taken into consideration in the study of nasal function ${ }^{(12,37)}$. The correlation between PNIF and PEF has been reported in healthy children ${ }^{(26)}$, but no multivariable analysis including PEF values was reported and FEV wasn't evaluated. As previously described ${ }^{(24-26)}$, we have found a correlation between PNIF and age, height and weight. PNIF values were higher in boys compared to girls but, as reported by Papachristou et al., this difference did not reach statistical significance until the age of 12 years ${ }^{(24)}$. Since age was the only variable consistently reported in the literature to be correlated with $\mathrm{PNIF}^{(23-27)}$, multivariable linear models for PNIF using this variable were presented. We chose to include baseline PEF rather than $\mathrm{FEV}_{1}$ in the final model since baseline PEF is more easily obtained, even with only a peak flow meter and without the need to use bronchodilators. After accounting for these variables, there still remains a large degree of variability in PNIF values, suggesting that further variables, such as anatomic variations or possibly nasal inflammation may refine the modelling of data. Using acoustic rhinometry (before and after alpha-agonist) and spirometry with bronchodilation test, Chawes and collaborators found an independent and consistent correlation between nasal volume and $\mathrm{FEV}_{1}$ in children aged six years ${ }^{(38)}$. In accordance to our results, the correlation between upper and lower airways measures were observed independently of rhinitis and asthma diagnosis ${ }^{(38)}$. This suggests that the independent correlation is a consistent finding in healthy and asthmatic children. Our results further support the hypothesis that the correlation between upper and lower airways may reflect a physiologic background for the common asthma-rhinitis multimorbidity ${ }^{(38)}$. 
Pathologic mechanisms could also be involved. A continuous nasobronchial inflammation process has been described in rhinitis and asthma ${ }^{(9,10)}$. However, we found no association between PNIF and FeNO levels or between reversibility of the upper and lower airways, also in agreement with Chawes et al findings ${ }^{(38)}$. We also found no differences in PNIF according to multiple sensitization to aeroallergens, as described before ${ }^{(38,39)}$. Nevertheless, Chawes and collaborators reported an association between blood eosinophil counts and nasal eosinophilia with nasal patency ${ }^{(38)}$, which we did not evaluate.

Our baseline PNIF values were similar to the reported values in healthy children in Brazil ${ }^{(25,26)}$. Prescott et al. and van Spronsen et al. reported slightly lower PNIF values ${ }^{(23,27)}$, while Papachristou et al., who analysed the largest sample of healthy children, reported higher PNIF values ${ }^{(24)}$. The discrepancy between study results could be due to different studied populations and to different methods (for instance, not performing the PNIF manoeuvre from the residual volume until reaching total lung capacity(23), or PNIF values collected while sitting ${ }^{(23,27)}$, or standing up $\left.{ }^{(24-26)}\right)$. A recent study in adults showed a trend towards a positive effect of the standing position on PNIF, although not statistically significant ${ }^{(40)}$. To our knowledge, the effect of body position on PNIF in children has not been analysed. Papachristou et al. published PNIF values were similar to our observed decongested PNIF values ${ }^{(24)}$, which we used as a reference.

In our study, no association was found between PNIF values and GINA asthma control or ARIA rhinitis classifications, or with CARATkids total or nasal scores. Previous studies with children have found an agreement between objective and subjective measures of nasal obstruction ${ }^{(21,41)}$, while others report the opposite ${ }^{(42)}$. The reason for this disagreement in multiple studies is probably multifactorial. For instance, given the known influence of other variables including age, gender and anthropometric variables in upper airway function in children, it is important to use reference values to obtain predicted percentages or ideally z-scores to interpret the results. We found an association between PNIF expressed in z-scores (for age and gender) and nasal obstruction self-report in the CARATkids questionnaire in children with allergic rhinitis and asthma. This association was also independent of PEF. Evaluating each nostril individually instead of bilateral measurements has been shown to allow stronger correlations between objective and subjective measurements in adults ${ }^{(13)}$, and also described in children using rhinomanometry ${ }^{(42)}$. On the other hand, the subjective scoring tool influences the results. Scales with fewer score options seem to increase the probability of an association between objective and subjective measurements ${ }^{(43)}$. The exact questions and time of symptoms evaluation may also affect this association. In our study, we didn't find statistically significant differences in PNIF comparing healthy children and children with rhinitis and asthma reporting nasal obstruction in the CARATkids question- naire. This needs to be analysed in future studies with larger samples, but it could be influenced by the fact that CARATkids questionnaire considers nasal symptoms self-reported by the children regarding the last two weeks and not necessarily current symptoms at the time of PNIF measurement. Moreover, in a previous study in adults, patients with asthma significantly rated their nasal obstruction by visual analogue scale more seriously than non-asthmatic controls with comparable PNIF values ${ }^{(29)}$. Apparently, the sensation of nasal obstruction in asthmatics may be different from controls despite being in the same PNIF group $^{(29)}$. On the opposite direction, children on long-term treatment for chronic rhinitis may underreport the amount of nasal congestion ${ }^{(44)}$, and it has been reported that children may be more accepting of mouth-breathing than adolescents ${ }^{(43)}$. Last but definitely not least, children might also be influenced by their parents or guardians' perceptions during the subjective assessments, which may also contribute to this disagreement ${ }^{(42)}$. Therefore, as in asthma, objective and subjective assessments appear to evaluate different parameters that may not be directly related, and PNIF may provide complementary information to the subjective evaluation of rhinitis and asthma in children. Since the subjective feeling of nasal obstruction may be valued differently by individual subjects, future research studies addressing PNIF in children with rhinitis and asthma may take advantage of additional comparisons with other measures of nasal patency, namely using the "golden standard" rhinomanometry.

\section{Conclusion}

In conclusion, the independent correlation between PNIF and lower airways patency measures in school-aged children suggests that, ideally, at least PEF values should be considered, besides age and gender, when evaluating nasal obstruction by means of PNIF in this age group. This study supports PNIF as a complementary objective measurement to the subjective assessment of allergic rhinitis and asthma control in children.

\section{Acknowledgement}

Funding: This work has been partially supported by a grant from AstraZeneca ${ }^{\oplus}$. Thermo Fisher Scientific, Inc. provided the materials for exhaled nitric oxide measurements. AstraZeneca ${ }^{\circledR}$ and Thermo Fisher Scientific, Inc. had no role in the study design, conduct of the research, preparation or submission of the article.

\section{Authorship contribution}

HP participated in study conception, data collection, analysis and interpretation and wrote the manuscript draft. LP, ACH, IM, CC, AVL and IA participated in data collection. MB provided critical review. MMA critically analysed the project, with guidance throughout its stages and tasks. All authors have reviewed and approved the final manuscript. 


\title{
Conflict of interest
}

\author{
None.
}

\section{References}

1. Brozek JL, Bousquet J, Agache I, et al. Allergic Rhinitis and its Impact on Asthma (ARIA) guidelines-2016 revision. J Allergy Clin Immunol. 2017; 140: 950-958.

2. Todo-Bom A, Loureiro C, Almeida MM, et al. Epidemiology of rhinitis in Portugal: evaluation of the intermittent and the persistent types. Allergy. 2007; 62: 1038-1043.

3. Morais-Almeida M, Santos N, Pereira AM, et al. Prevalence and classification of rhinitis in preschool children in Portugal: a nationwide study. Allergy. 2013; 68: 1278-1288.

4. Morais-Almeida M, Pite $H$, Pereira AM, et al. Prevalence and classification of rhinitis in the elderly: a nationwide survey in Portugal. Allergy. 2013; 68: 1150-1157.

5. Pite H, Gaspar A, Morais-Almeida M. Preschool-age wheezing phenotypes and asthma persistence in adolescents. Allergy Asthma Proc. 2016; 37: 231-241.

6. Pereira AM, Morais-Almeida M, Santos N, Nunes C, Bousquet J, Fonseca JA. Severity of rhinitis and wheezing is strongly associated in preschoolers: A population-based study. Pediatr Allergy Immunol. 2015; 26: 618-627.

7. Pite $H$, Pereira AM, Morais-Almeida M, Nunes C, Bousquet J, Fonseca JA Prevalence of asthma and its association with rhinitis in the elderly. Respir Med. 2014; 108: 1117-1126.

8. Bousquet J, Khaltaev N, Cruz AA, et al. Allergic Rhinitis and its Impact on Asthma (ARIA) 2008 update (in collaboration with the World Health Organization, GA(2)LEN and AllerGen). Allergy. 2008; 63: 8-160.

9. Bousquet J, Schunemann HJ, Samolinski $B$, et al. Allergic Rhinitis and its Impact on Asthma (ARIA): achievements in 10 years and future needs. J Allergy Clin Immunol. 2012; 130: 1049-1062.

10. From the Global Strategy for Asthma Management and Prevention, Global Initiative for Asthma (GINA) 2017. Available from: http://www.ginasthma.org/. (last accessed 22 January 2018).

11. Scadding G, Hellings $P$, Alobid I, et al. Diagnostic tools in Rhinology EAACl position paper. Clin Transl Allergy. 2011; 1:2.

12. Ottaviano G, Fokkens WJ. Measurements of nasal airflow and patency: a critical review with emphasis on the use of peak nasal inspiratory flow in daily practice. Allergy. 2016; 71: 162-174.

13. Andre RF, Vuyk HD, Ahmed A, Graamans K, Nolst Trenite GJ. Correlation between subjective and objective evaluation of the nasal airway. A systematic review of the highest level of evidence. Clin Otolaryngol. 2009; 34: 518-525.

14. Fonseca JA, Nogueira-Silva L, MoraisAlmeida $M$, et al. Validation of a questionnaire (CARAT10) to assess rhinitis and asth- ma in patients with asthma. Allergy. 2010; 65: 1042-1048.

15. Linhares DV, da Fonseca JA, Borrego LM, et al. Validation of control of allergic rhinitis and asthma test for children (CARATKids)-a prospective multicenter study. Pediatr Allergy Immunol. 2014; 25: 173-179.

16. Borrego LM, Fonseca JA, Pereira AM, Pinto VR, Linhares D, Morais-Almeida M. Development process and cognitive testing of CARATkids - Control of Allergic Rhinitis and Asthma Test for children. BMC Pediatr. 2014; 14: 34.

17. Kirtsreesakul V, Leelapong J, Ruttanaphol S. Nasal peak inspiratory and expiratory flow measurements for assessing nasal obstruction in allergic rhinitis. Am J Rhinol Allergy. 2014; 28: 126-130.

18. Martins de Oliveira GM, Rizzo JA, Camargos PA, Sarinho ES. Are measurements of peak nasal flow useful for evaluating nasal obstruction in patients with allergic rhinitis? Rhinology. 2015; 53: 160-166.

19. Wilson A, Dempsey OJ, Sims EJ, Coutie WJ, Paterson MC, Lipworth BJ. Evaluation of treatment response in patients with seasonal allergic rhinitis using domiciliary nasal peak inspiratory flow. Clin Exp Allergy. 2000; 30: 833-838.

20. Scadding GW, Eifan AO, Lao-Araya M, et al. Effect of grass pollen immunotherapy on clinical and local immune response to nasal allergen challenge. Allergy. 2015; 70: 689-696.

21. de Souza Campos Fernandes S, Ribeiro de Andrade C, da Cunha Ibiapina C. Application of Peak Nasal Inspiratory Flow reference values in the treatment of allergic rhinitis. Rhinology. 2014; 52: 133-136.

22. Jordana G, Dolovich J, Briscoe MP, et al. Intranasal fluticasone propionate versus loratadine in the treatment of adolescent patients with seasonal allergic rhinitis. J Allergy Clin Immunol. 1996; 97: 588-595.

23. Prescott CA, Prescott KE. Peak nasal inspiratory flow measurement: an investigation in children. Int J Pediatr Otorhinolaryngol. 1995; 32: 137-141.

24. Papachristou A, Bourli E, Aivazi D, et al Normal peak nasal inspiratory flow rate values in Greek children and adolescents. Hippokratia. 2008; 12: 94-97.

25. da Cunha Ibiapina C, Ribeiro de Andrade C, Moreira Camargos PA, Goncalves Alvim C, Augusto Cruz A. Reference values for peak nasal inspiratory flow in children and adolescents in Brazil. Rhinology. 2011; 49: 304-308.

26. Chaves C, Ibiapina Cda C, de Andrade CR, Godinho R, Alvim CG, Cruz AA. Correlation between peak nasal inspiratory flow and peak expiratory flow in children and adolescents. Rhinology. 2012; 50: 381-385.
27. van Spronsen E, Ebbens FA, Fokkens WJ. Normal peak nasal inspiratory flow rate values in healthy children aged 6 to 11 years in the Netherlands. Rhinology. 2012; 50: 22-25.

28. Ottaviano G, Lund VJ, Coles S, Staffieri A, Scadding GK. Does peak nasal inspiratory flow relate to peak expiratory flow? Rhinology. 2008; 46: 200-203.

29. Thorstensen WM, Sue-Chu M, Bugten V, Cvancarova M, Steinsvag SK. The determining factors of peak nasal inspiratory flow and perception of nasal airflow in asthmatics. Rhinology. 2014; 52: 348-354.

30. Nathan RA, Eccles R, Howarth PH, Steinsvag SK, Togias A. Objective monitoring of nasal patency and nasal physiology in rhinitis. J Allergy Clin Immunol. 2005; 115: S442-S459.

31. Asher MI, Keil U, Anderson HR, et al. International Study of Asthma and Allergies in Childhood (ISAAC): rationale and methods. Eur Respir J. 1995; 8: 483-491.

32. Miller MR, Hankinson J, Brusasco V, et al. Standardisation of spirometry. Eur Respir J. 2005; 26: 319-338.

33. Kjaergaard T, Cvancarova M, Steinsvag SK. Nasal congestion index: A measure for nasal obstruction. Laryngoscope. 2009; 119: 1628-1632.

34. ATS/ERS recommendations for standardized procedures for the online and offline measurement of exhaled lower respiratory nitric oxide and nasal nitric oxide, 2005. Am J Respir Crit Care Med. 2005; 171: 912-930.

35. Horvath I, Barnes PJ, Loukides S, et al. A European Respiratory Society technical standard: exhaled biomarkers in lung disease. Eur Respir J. 2017; 49: 1600965.

36. Heinzerling L, Mari A, Bergmann KC, et al. The skin prick test - European standards. Clin Transl Allergy. 2013; 3: 3.

37. Chaves C, de Andrade CR, Ibiapina C. Objective measures for functional diagnostic of the upper airways: practical aspects. Rhinology. 2014; 52: 99-103.

38. Chawes BL, Kreiner-Moller E, Bisgaard $H$. Upper and lower airway patency are associated in young children. Chest. 2010; 137: 1332-1337.

39. Thorstensen WM, Sue-Chu M, Bugten V, Steinsvag SK. Nasal flow, volumes, and minimal cross sectional areas in asthmatics. Respir Med. 2013; 107: 1515-1520.

40. Ottaviano G, Scadding GK, lacono V, Scarpa B, Martini A, Lund VJ. Peak nasal inspiratory flow and peak expiratory flow. Upright and sitting values in an adult population. Rhinology. 2016; 54: 160-163.

41. Gomes Dde L, Camargos PA, Ibiapina Cda C, de Andrade CR. Nasal peak inspiratory flow and clinical score in children and adolescents with allergic rhinitis. Rhinology. 2008; 46: 276-280.

42. Mendes AI, Wandalsen GF, Sole D. Objective 
and subjective assessments of nasa obstruction in children and adolescents with allergic rhinitis. J Pediatr (Rio J). 2012; 88: 389-395.

43. Watson WT, Roberts JR, Becker $A B$, Gendreau-Reid LF, Simons FE. Nasal patency in children with allergic rhinitis: correlation of objective and subjective assessments. Ann Allergy Asthma Immunol. 1995; 74: 237-240.

44. Priftis KN, Drigopoulos K, Sakalidou A, Triga $M$, Kallis V, Nicolaidou P. Subjective and objective nasal obstruction assessment in children with chronic rhinitis. Int J Pediatr Otorhinolaryngol. 2006; 70: 501-505.
Helena Pité, MD

Allergy Center

CUF-Descobertas Hospital

Rua Mário Botas

1998-018 Lisbon

Portugal

Tel. +351962790162

Fax. +351210025220

E-mail: helenampite@gmail.com 